\title{
PAPER \\ A Coupled Dynamical Model of Redox Flow Battery Based on Chemical Reaction, Fluid Flow, and Electrical Circuit
}

\author{
Minghua $\mathrm{LI}^{\dagger \mathrm{a})}$, Nonmember and Takashi HIKIHARA ${ }^{\dagger, \dagger \mathrm{b})}$, Member
}

\begin{abstract}
SUMMARY The redox (Reduction-Oxidation) flow battery is one of the most promising rechargeable batteries due to its ability to average loads and output of power sources. The transient characteristics are well known as the remarkable feature of the battery. Then it can also compensate for a sudden voltage drop. The dynamics are governed by the chemical reactions, fluid flow, and electrical circuit of its structure. This causes the difficulty of the analysis at transient state. This paper discusses the transient behavior of the redox flow battery based on chemical reactions. The concentration change of vanadium ions depends on the chemical reactions and the flow of electrolysis solution. The chemical reaction rate is restricted by the attached external electric circuit. In this paper, a model of the transient behavior is introduced. The validity of the derived model is examined based on experiments for a tested micro-redox flow battery system.

key words: redox flow battery, rechargeable battery, dynamical model, chemical reaction rate, fluid flow, simulation
\end{abstract}

\section{Introduction}

Recently, rechargeable batteries have been recognized as one of the key elements for both applying distributed power sources and regulating power networks [1]-[3]. Redox flow batteries have the ability to average generated power, to level loads, and to operate as an uninterruptible power system. It is, in particular, recognized as a voltage compensator with high-speed response characteristics [3]. The redox flow battery has a remarkable structure in which tanks and charging/discharging cells are separately placed. It gives the battery advantageous flexibility for the design of ampere-hour capacity. Any dynamical models, however, have not been established with consideration to the complex relationships amongst electrical, chemical, and fluid dynamics under the structural restrictions [3]-[10]. Therefore, it is inevitable to focus on the derivation of the dynamical model of the redox flow battery system for the development and control.

In this paper, a dynamical model of the redox flow battery is proposed based on physical phenomena and chemical kinetics. The concentration change of ions is governed by the chemical reaction, the flow rate of electrolysis solution, and also restricted by the externally attached circuit behavior. Therefore the system model becomes the highly complex relation of multi time scale dynamics. Based on the

\footnotetext{
Manuscript received December 10, 2007.

Manuscript revised March 18, 2008.

${ }^{\dagger}$ The authors are with the Department of Electrical Engineering, Kyoto University, Kyoto-shi, 615-8510 Japan.

${ }^{\dagger}$ The author is with the Photonic and Electronic Science and Engineering Center, Kyoto University, Kyoto-shi, 615-8510 Japan.

a)E-mail: li@dove.kuee.kyoto-u.ac.jp

b) E-mail: hikihara@kuee.kyoto-u.ac.jp

DOI: 10.1093/ietfec/e91-a.7.1741
}

model, the simulated results of dynamics are experimentally examined. The validation of the model has been confirmed, quantitatively and qualitatively. Moreover, the model is general and free from the limitation of the capacity of the tested battery. Therefore it can, hopefully, be applied to adjust the operating parameters of batteries and the design of control strategy for transient operation.

\section{Concentration Change and Output Voltage of the Redox Flow Battery}

\subsection{Electrode Reaction and Configuration of the Redox} Flow Battery

A redox flow battery is charged and discharged by valence change of vanadium ions. When the current flows through the electrode, the electrode reaction is given by the following relations [6], [11]-[14]. Positive electrode reaction is:

$$
\mathrm{VO}_{2}^{+}+2 \mathrm{H}^{+}+\mathrm{e}^{-} \leftrightarrow \mathrm{VO}^{2+}+\mathrm{H}_{2} \mathrm{O}
$$

and negative electrode reaction is:

$$
\mathrm{V}^{2+} \leftrightarrow \mathrm{V}^{3+}+\mathrm{e}^{-} .
$$

$\mathrm{VO}_{2}{ }^{+}$is in the positive electrode and $\mathrm{V}^{2+}$ is in the negative electrode. Therefore, they transform themselves to $\mathrm{VO}^{2+}$ and $\mathrm{V}^{3+}$ at discharging operation. In the process $\mathrm{H}^{+}$moves from the negative electrode to the positive through the ionexchange membrane at the same time that $\mathrm{e}^{-}$moves from the negative electrode to the positive through the external circuit. It has the reverse reaction, in charging operation.

A redox flow battery has the remarkable structure consisting of cells and separated tanks. They have the positive elements and negative ones separately. The electrolysis solution is circulated by pumps between battery cells and tanks in both circulation circuits. The concentration of ions is governed by the electrode reactions and flow of electrolysis solution. However, the concentration change in the cell becomes small because of the pressured electrolysis solution by pumps. Figure 1 shows the schematic diagram of the discharging circuit, reaction cell, and circulatory system for electrolysis solution in the redox flow battery. In the system, charging and discharging process can be switched by the direction of external electrical current. The direction becomes reverse in both operations. The load resistance is set null at charging operation. 


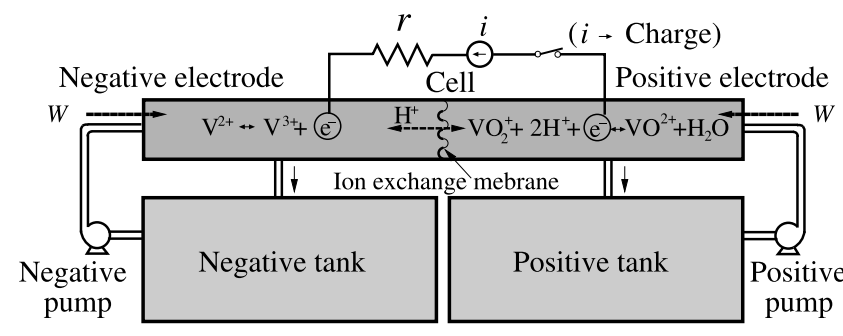

Fig. 1 Schematic diagram of discharging circuit, reaction cell, and circulatory system for electrolysis solution in the redox flow battery.

Table 1 Nomenclature.

\begin{tabular}{|c|c|}
\hline$\alpha_{\mathrm{T}}$ & volume of $\operatorname{tank}(\mathrm{L})$ \\
\hline$\alpha_{\mathrm{C}}$ & volume of cell (L) \\
\hline$k_{1}$ & reaction rate constant in positive electrode $\left(\mathrm{L}^{3} \cdot \mathrm{mol}^{-3} \cdot \mathrm{s}^{-1}\right)$ \\
\hline$k_{2}$ & reaction rate constant in negative electrode $\left(\mathrm{s}^{-1}\right)$ \\
\hline$[\cdot]$ & concentration of ion $\left(\mathrm{mol} \cdot \mathrm{L}^{-1}\right)$ \\
\hline$i$ & charge/discharge current (A) \\
\hline$E_{\mathrm{e}}$ & standard electromotive force $(\mathrm{V})$ \\
\hline$E_{\mathrm{eC}}$ & no-load voltage (V) \\
\hline$E_{\mathrm{e}}^{0}$ & $\begin{array}{l}\text { standard electromotive force based on } \\
\text { the concentration of hydrogen ion }(\mathrm{V})\end{array}$ \\
\hline$E_{\mathrm{C}}$ & on-load voltage $(\mathrm{V})$ \\
\hline$T$ & temperature $(\mathrm{K})$ \\
\hline$W$ & flow rate $\left((1 / 12) \cdot \mathrm{L} \cdot \mathrm{s}^{-1}\right)$ \\
\hline$r$ & load resistance $(\Omega)$ \\
\hline$\omega$ & angular frequency $\left(\mathrm{rad} \cdot \mathrm{s}^{-1}\right)$ \\
\hline$\beta$ & impedance of battery $(\Omega)$ \\
\hline$N$ & number of $\mathrm{V}^{2+}$ \\
\hline$N_{\mathrm{A}}$ & Avogadro's number $\left(6.02 \times 10^{23} \mathrm{~mol}^{-1}\right)$ \\
\hline$F$ & Faraday constant $\left(9.65 \times 10^{4} \mathrm{C} \cdot \mathrm{mol}^{-1}\right)$ \\
\hline $\begin{array}{c}{\left[\mathrm{V}_{\max }\right]} \\
R\end{array}$ & $\begin{array}{l}\text { maximal concentration of vanadium ions }\left(1.7 \mathrm{~mol} \cdot \mathrm{L}^{-1}\right) \\
\text { gas constant }\left(8.31 \mathrm{~J} \cdot \mathrm{K}^{-1} \cdot \mathrm{mol}^{-1}\right)\end{array}$ \\
\hline
\end{tabular}

\subsection{Concentration Change under Constant Flow}

As mentioned above the concentration change of ions is governed by chemical reactions, flow of electrolysis solution, and the restriction of electrical circuit. In the following discussion, it is assumed that both the time delay of electrolysis solution flow in tube and the mixing time at cells and tanks are neglected for simplicity. The chemical reaction rate at charging and discharging is also assumed to be the same. Similarly, the flow rates in both electrodes are assumed to be balanced. Then, the concentration change of $\mathrm{VO}^{2+}$ is given by:

$$
\begin{aligned}
\frac{\mathrm{d}\left[\mathrm{VO}_{2}{ }^{+}\right]_{\mathrm{C}}}{\mathrm{d} t}= & \mp k_{1}\left[\mathrm{VO}_{2}{ }^{+}\right]_{\mathrm{C}}\left[\mathrm{H}^{+}\right]_{\mathrm{C}+}^{2}\left[\mathrm{e}^{-}\right]_{+} \\
& +\frac{W}{\alpha_{\mathrm{C}}}\left\{\left[\mathrm{VO}_{2}{ }^{+}\right]_{\mathrm{T}}-\left[\mathrm{VO}_{2}{ }^{+}\right]_{\mathrm{C}}\right\},
\end{aligned}
$$

where [.] denotes the reactant concentration and $k_{1}$ is the chemical reaction rate. Table 1 shows the nomenclature. The concentration change of vanadium ion consists of the chemical reaction and the electrolysis solution circulation. The first term shows the concentration change which comes from the chemical reaction. The signs "-" and "+" imply that the concentration of cells and tanks decreases during discharge operation and increases during charging operation, respectively. The second term corresponds to the concentration change by the electrolysis circulation. This term is governed by the difference of concentration in tanks and cells, the flow rate of electrolysis solution, and the volume of cell. The concentration change of the vanadium ion of $\mathrm{V}^{2+}$ based on Eq. (2) is given by:

$$
\frac{\mathrm{d}\left[\mathrm{V}^{2+}\right]_{\mathrm{C}}}{\mathrm{d} t}=\mp k_{2}\left[\mathrm{~V}^{2+}\right]_{\mathrm{C}}+\frac{W}{\alpha_{\mathrm{C}}}\left\{\left[\mathrm{V}^{2+}\right]_{\mathrm{T}}-\left[\mathrm{V}^{2+}\right]_{\mathrm{C}}\right\} .
$$

The concentration change of other ions can be modeled in the same way. Moreover, the relationship between the concentration of $\mathrm{V}^{2+}$ and the current obeys:

$$
\mp k_{2}\left[\mathrm{~V}^{2+}\right]_{\mathrm{C}}=\mp k_{1}\left[\mathrm{VO}_{2}{ }^{+}\right]_{\mathrm{C}}\left[\mathrm{H}^{+}\right]_{\mathrm{C}+}^{2}\left[\mathrm{e}^{-}\right]_{+}=\mp \frac{i}{\alpha_{\mathrm{C}} F} .
$$

The above equation is held in charging and discharging operation. The following discusses the concentration of $\mathrm{V}^{2+}$ because the concentration of $\mathrm{V}^{2+}$ is same as $\mathrm{VO}_{2}{ }^{+}$. In the redox flow battery, the total number of $\mathrm{V}^{2+}$ coincides with the quantity in cells and tanks. Then, in charging and discharging operation, the following conservation relationship is held:

$$
\alpha_{\mathrm{C}}\left[\mathrm{V}^{2+}\right]_{\mathrm{C}}+\alpha_{\mathrm{T}}\left[\mathrm{V}^{2+}\right]_{\mathrm{T}}=\frac{N}{N_{\mathrm{A}}} .
$$

The current $i$ in external electrical circuit governs the number of $\mathrm{V}^{2+}$ as follows:

$$
\frac{1}{N_{\mathrm{A}}} \frac{\mathrm{d} N}{\mathrm{~d} t}=\mp \frac{i}{F} \text {. }
$$

The concentration change of vanadium ion $\mathrm{V}^{2+}$ is given in the cells by the following equation:

$$
\begin{aligned}
\frac{\mathrm{d}^{2}\left[\mathrm{~V}^{2+}\right]_{\mathrm{C}}}{\mathrm{d} t^{2}}= & -\left\{W\left(\frac{1}{\alpha_{\mathrm{T}}}+\frac{1}{\alpha_{\mathrm{C}}}\right)-\frac{1}{W} \frac{\mathrm{d} W}{\mathrm{~d} t}\right\} \frac{\mathrm{d}\left[\mathrm{V}^{2+}\right]_{\mathrm{C}}}{\mathrm{d} t} \\
& \mp \frac{1}{\alpha_{\mathrm{C}} F} \frac{\mathrm{d} i}{\mathrm{~d} t} \mp\left(\frac{W}{\alpha_{\mathrm{T}}}-\frac{1}{W} \frac{\mathrm{d} W}{\mathrm{~d} t}\right) \frac{1}{\alpha_{\mathrm{C}}} \frac{i}{F} .
\end{aligned}
$$

At constant flow rate $W_{0}$ the model Eq. (8) is simplified as:

$$
\begin{aligned}
\frac{\mathrm{d}^{2}\left[\mathrm{~V}^{2+}\right]_{\mathrm{C}}}{\mathrm{d} t^{2}}= & -W_{0}\left(\frac{1}{\alpha_{\mathrm{T}}}+\frac{1}{\alpha_{\mathrm{C}}}\right) \frac{\mathrm{d}\left[\mathrm{V}^{2+}\right]_{\mathrm{C}}}{\mathrm{d} t} \mp \frac{1}{\alpha_{\mathrm{C}} F} \frac{\mathrm{d} i}{\mathrm{~d} t} \\
& \mp \frac{W_{0}}{\alpha_{\mathrm{T}} \alpha_{\mathrm{C}}} \frac{i}{F} .
\end{aligned}
$$

Here, the concentration of the vanadium ion in the tank is governed by:

$$
\frac{\mathrm{d}\left[\mathrm{V}^{2+}\right]_{\mathrm{T}}}{\mathrm{d} t}=\frac{1}{\alpha_{\mathrm{T}}}\left\{-\alpha_{\mathrm{C}} \frac{\mathrm{d}\left[\mathrm{V}^{2+}\right]_{\mathrm{C}}}{\mathrm{d} t} \mp \frac{i}{F}\right\} .
$$

Equations (9) and (10) are derived based on the abovementioned principle of operation. In the next section, there is introduced the relationship between the output terminal voltage of the redox flow battery and the concentration change. 


\subsection{Output Terminal Voltage of the Redox Flow Battery}

The no-load voltage of the redox flow battery $E_{\mathrm{eC}}$ is given by the Nernst's equation based on concentration of electrolysis solution in cells [6]-[9].

$$
E_{\mathrm{eC}}=E_{\mathrm{e}}+\frac{R T}{F} \ln \frac{\left[\mathrm{V}^{2+}\right]_{\mathrm{C}}\left[\mathrm{VO}_{2}{ }^{+}\right]_{\mathrm{C}}\left[\mathrm{H}^{+}\right]_{\mathrm{C}+}\left[\mathrm{H}^{+}\right]_{\mathrm{C}+}}{\left[\mathrm{V}^{3+}\right]_{\mathrm{C}}\left[\mathrm{VO}^{2+}\right]_{\mathrm{C}}}
$$

The Nernst's relation used to be applied for describing equilibrium states. However, our previous experimental results assured that it can be extended to model dynamical equilibrium states [7]-[9]. Here, it is assumed that the concentration of vanadium ion keeps the equal amount in both positive and negative electrode as mentioned above. Moreover, the concentration of hydrogen ion is also assumed to be neglected in tanks and cells. Then the following electrical relationships are held:

$$
E_{\mathrm{eC}}=E_{\mathrm{e}}^{0}+\frac{2 R T}{F} \ln \frac{\left[\mathrm{V}^{2+}\right]_{\mathrm{C}}}{\left[\mathrm{V}_{\max }\right]-\left[\mathrm{V}^{2+}\right]_{\mathrm{C}}},
$$

where $E_{\mathrm{e}}^{0}$ corresponds to a standard electromotive force with consideration to the concentration of hydrogen ion and $\left[\mathrm{V}_{\max }\right]$ is the maximal concentration of vanadium ions. On the other hand, the on-load voltage is decided through the circuit relation:

$$
E_{\mathrm{C}}=E_{\mathrm{eC}} \mp i(r+\beta) .
$$

As a result, the dynamical characteristics of the redox flow battery can be estimated by Eqs. (9), (10), (12), and (13), numerically.

\section{Model Equation and Validity}

In the previous section, a model equation of the redox flow battery was obtained. Here, the validity of the model is discussed based on experiments and numerical simulations.

\subsection{Model for Constant Flow Rate}

Here, we summarize the dynamical relationship of the redox flow battery at the state under constant flow. Table 2 shows the nomenclature of variables, parameters, and constants. In the following equations, their dimensions remain. The concentration change in cell is depicted by Eq. (9).

$$
\frac{\mathrm{d}^{2} x_{1}}{\mathrm{~d} t^{2}}+W_{0}\left(\frac{1}{\mu_{1}}+\frac{1}{\mu_{2}}\right) \frac{\mathrm{d} x_{1}}{\mathrm{~d} t} \pm \frac{1}{\mu_{1} F} \frac{\mathrm{d} x_{3}}{\mathrm{~d} t} \pm \frac{W_{0}}{\mu_{1} \mu_{2}} \frac{x_{3}}{F}=0
$$

The concentration change in tank is also given by Eq. (10).

$$
\frac{\mathrm{d} x_{2}}{\mathrm{~d} t}+\frac{1}{\mu_{2}}\left\{\mu_{1} \frac{\mathrm{d} x_{1}}{\mathrm{~d} t} \pm \frac{x_{3}}{F}\right\}=0
$$

The no-load voltage is depicted by Eq. (12).
Table 2 Nomenclature of variables, parameters, and constants in the model Eqs. (14)-(17).

\begin{tabular}{|c|c|}
\hline$x_{1}$ & concentration of $\mathrm{V}^{2+}$ in cell \\
$x_{2}$ & concentration of $\mathrm{V}^{2+}$ in tank \\
$x_{3}$ & charging/discharging current \\
$x_{4}$ & no-load voltage \\
$x_{5}$ & on-load voltage \\
$\mu_{1}$ & volume of cell \\
$\mu_{2}$ & volume of tank \\
$\mu_{3}$ & maximal concentration of vanadium \\
$\mu_{4}$ & load resistance \\
$\mu_{5}$ & impedance of battery \\
$E_{\mathrm{e}}^{0}$ & standard electromotive force based on \\
$W_{0}$ & the concentration of hydrogen ion \\
\hline
\end{tabular}

$$
x_{4}=E_{\mathrm{e}}^{0}+\frac{2 R T}{F} \ln \frac{x_{1}}{\mu_{3}-x_{1}}
$$

The no-load voltage is also from Eq. (13).

$$
x_{5}=x_{4} \mp x_{3}\left(\mu_{4}+\mu_{5}\right)
$$

Equations (14)-(17) give the dynamical model of the redox flow battery based on chemical reaction with constant flow and the restriction of electrical circuit. In order to achieve the flow rate control in the system, the model can easily be extended to include the dynamics of $W$.

\subsection{Validity of Dynamical Model}

Here, the validity of the model is confirmed with comparison to experimental results. If the current $x_{3}$ is kept constant in Eq. (14), the concentration change in cells follows:

$$
\frac{\mathrm{d}^{2} x_{1}}{\mathrm{~d} t^{2}}+W_{0}\left(\frac{1}{\mu_{1}}+\frac{1}{\mu_{2}}\right) \frac{\mathrm{d} x_{1}}{\mathrm{~d} t} \pm \frac{W_{0}}{\mu_{1} \mu_{2}} \frac{x_{3}}{F}=0 .
$$

In this simulation, the flow rate of electrolysis solution is set at $3.5 / 12 \mathrm{~L} / \mathrm{min}$, charging/discharging current at $35.0 \mathrm{~A}$, and electrolysis solution temperature at $35.0^{\circ} \mathrm{C}$. Here 12 denotes the number of cells which share the solution flow. Therefore, the flow rate is averaged at $3.5 / 12 \mathrm{~L} / \mathrm{min}$ for one cell. In charging simulation the initial values of concentrations of $\mathrm{V}^{2+}$ is given at $1.7 \mathrm{~mol} / \mathrm{L}$. In discharging simulation, the concentrations of $\mathrm{V}^{2+}$ is set at $0.0 \mathrm{~mol} / \mathrm{L}$.

Figure 2 shows $x_{1}=\left[\mathrm{V}^{2+}\right]_{\mathrm{C}}$ and $x_{2}=\left[\mathrm{V}^{2+}\right]_{\mathrm{T}}$ based on Eqs. (15) and (18). The no-load voltage $x_{4}=E_{\mathrm{eC}}$ and the on-load voltage $x_{5}=E_{\mathrm{C}}$ are obtained from Eqs. (16) and (17). However, the internal resistance $\mu_{5}$ in both operations are set at an experimentally obtained value. During charging operation $\mu_{5}$ is $0.00245 \Omega$ and during discharging operation $0.0028 \Omega[8] .\left[\mathrm{V}^{2+}\right]_{\mathrm{C}}$ and $\left[\mathrm{V}^{2+}\right]_{\mathrm{T}}$ increase during the charging period. Meanwhile they decrease during the discharging period. The tanks obviously have higher concentrations than cells at charging operation. On the contrary, the concentrations in tanks is lower than in cells at discharging operation. This implies that the electrolysis solution is continuously supplied from tanks to cells. Simultaneously, the voltage increases in charging and decreases in discharging 
monotonously. Hence, it qualitatively satisfies the principle mechanism of the redox flow battery and the model holds its validity.

Figure 3 shows the simulated results of output voltage with experimental results. We have confirmed that the simulated results agree with experimental data for other current conditions. In this paper, one case is shown for discussion. In the figure, the flow rate of electrolysis solution is set at $3.5 \mathrm{~L} / \mathrm{min}$, charging/discharging current at $36.4 \mathrm{~A}$. Here the flow rate is also averaged at $3.5 / 12 \mathrm{~L} / \mathrm{min}$ for one cell. The charging and discharging operations are decided by a threshold output voltage $1.55 \mathrm{~V}$. The results clearly show the quantitative coincidence between simulations and experiments. However, there are still some differences for the timing of transition and voltage drop after the long discharging operation. The transition timing is given by the threshold of output voltage. Then the increase of ion concentration governs the switching automatically in simulations and experiments.

In this section, simulations were performed at constant current and constant flow rate. The simulated results show the wonderful coincidence with experimental results. It shows the validity of the proposed model. Therefore, it can be concluded that the dynamical model can be applied for the simulation of the battery characteristics. The switching time is decided by the output voltage. Then the delay

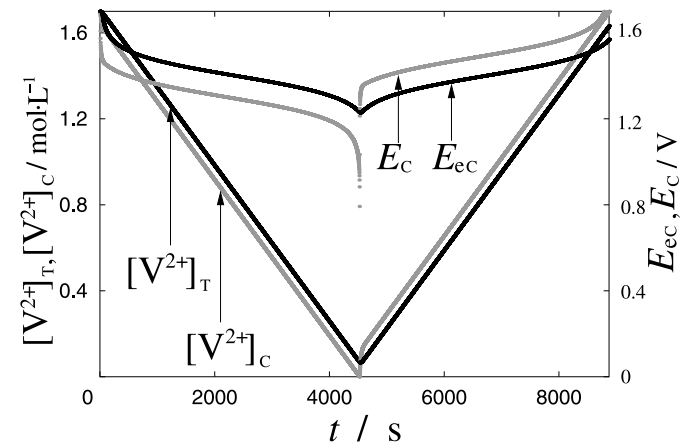

Fig. $2\left[\mathrm{~V}^{2+}\right]_{\mathrm{T}}$ and $\left[\mathrm{V}^{2+}\right]_{\mathrm{C}}$ at charging/discharging operation, with comparison to simulated results $E_{\mathrm{C}}$ and $E_{\mathrm{eC}}$. Here $E_{\mathrm{C}}$ denotes the on-load voltage, and $E_{\mathrm{eC}}$ does the no-load voltage.

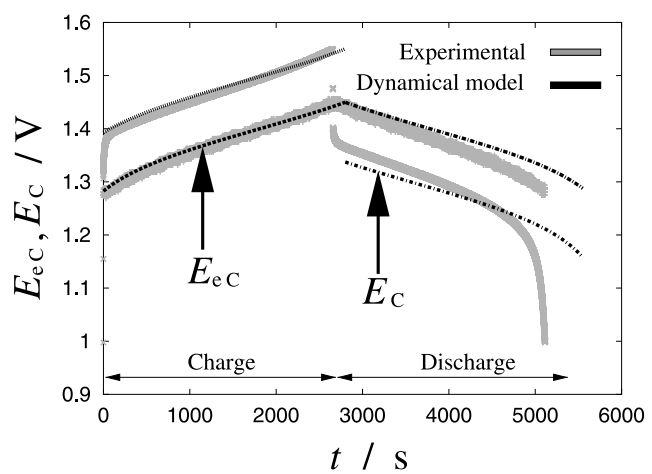

Fig. 3 Simulated and experimental results of output voltage at on-load and no-load (3.5 L/min, 36.4 A). Simulations are performed by Eqs. (16) and (17). shows that there still remains the difference of the estimation in states. The voltage drop in experimental discharging process shows apparent differences from the simulated results. It is considered the drop in experiments dues to the capacity of solution in cells and tanks.

\section{Simulated Characteristics of the Redox Flow Bat- tery}

\subsection{Output Terminal Voltage under Load Disturbance}

In this section the output characteristics of battery are examined for the load disturbance through the proposed model. Figure 4 shows the schematic discharging circuit. The model equation is derived based on Eq. (14). Here the current begins to change at the instant the switch is turned on. The current follows:

$$
\frac{\mathrm{d} x_{3}}{\mathrm{~d} t}-\frac{1}{L}\left\{x_{4}-\left(r_{1}+r_{2}\right) x_{3}\right\}=0 .
$$

The concentration of cells is described according to Eq. (14) with positive sign.

$$
\begin{aligned}
\frac{\mathrm{d}^{2} x_{1}}{\mathrm{~d} t^{2}} & +\frac{1}{\mu_{1} F L}\left\{x_{4}+\left(\frac{W_{0} L}{\mu_{2}}-r_{1}-r_{2}\right) x_{3}\right\} \\
& +\left(\frac{W_{0}}{\mu_{1}}+\frac{W_{0}}{\mu_{2}}\right) \frac{\mathrm{d} x_{1}}{\mathrm{~d} t}=0 .
\end{aligned}
$$

Table 3 denotes the circuit parameters for simulations. Figure 5 shows the simulated output voltages of the redox flow battery after the disturbance. The initial concentration of electrolysis solution in cell is set at $0.2 \mathrm{~mol} / \mathrm{L}$. When the switch is turned on, the different flow rates are given in simulations. If the flow rate becomes high, the output voltage becomes high and the discharging time long. That is, the voltage holds higher when the flow is kept at an appropriate rate. The discharging time can be kept longer and ampere-hour capacity higher simultaneously. It shows that

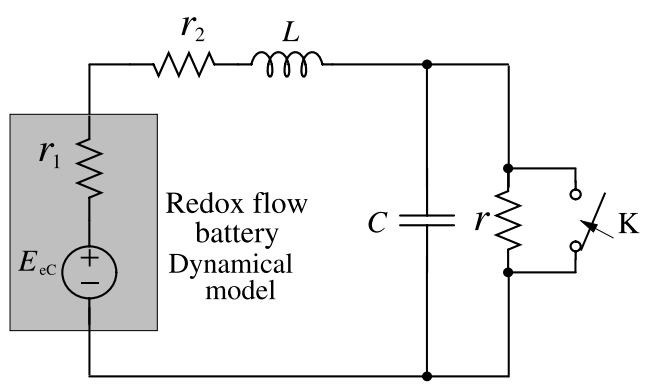

Fig. 4 Discharging circuit of the redox flow battery.

Table 3 Circuit parameters.

\begin{tabular}{|c|c|}
\hline$r_{1}$ & $0.0028 \Omega$ \\
$r_{2}$ & $0.0128 \Omega$ \\
$r$ & $0.05 \Omega$ \\
$C$ & $1.0 \mathrm{~F}$ \\
$L$ & $0.1 \mathrm{H}$ \\
\hline
\end{tabular}




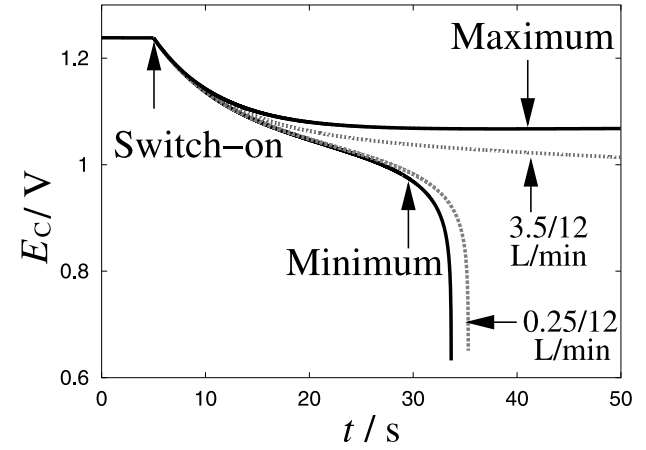

Fig. 5 Flow rate dependency of output voltage of the redox flow battery.

the availability of ampere-hour capacity of the battery can be improved by control of the flow rate. The voltage can be adjusted in the region between the maximum and minimum line under control. In other words, it is difficult to expect higher voltage over the maximum value.

\subsection{Frequency Response Characteristics}

In this section, the frequency response characteristics of the redox flow battery are discussed for the sinusoidally fluctuated current during the charging operation. The setup corresponds to a case in practical use. Here, we give the charging current $x_{3}$ by:

$$
x_{3}=i_{0}(1+\gamma \sin \omega t) .
$$

Then the model equation Eq. (14) is revised as:

$$
\begin{aligned}
\frac{\mathrm{d}^{2} x_{1}}{\mathrm{~d} t^{2}}+W_{0}\left(\frac{1}{\mu_{1}}+\frac{1}{\mu_{2}}\right) \frac{\mathrm{d} x_{1}}{\mathrm{~d} t}-\frac{i_{0} \gamma \omega \cos \omega t}{\mu_{1} F} \\
-\frac{W_{0} i_{0}(1+\gamma \sin \omega t)}{\mu_{1} \mu_{2} F}=0 .
\end{aligned}
$$

Then the concentration change $y\left(=\frac{\mathrm{d} x_{1}}{\mathrm{~d} t}\right)$ becomes:

$$
y=\frac{i_{0}}{F}\{1+K \sin (\omega t+\delta)\}+\frac{i_{0}}{F}\left(\frac{\mu_{2}}{\mu_{1}}-K \sin \delta\right) e^{-\frac{W_{0}}{\mu_{1} \mu_{2}} t},
$$

where,

$$
\begin{aligned}
& K=\gamma \frac{\sqrt{1+\left(\frac{\mu_{2} \omega}{W_{0}}\right)^{2}}}{\sqrt{1+\left(\frac{\mu_{1} \mu_{2} \omega}{W_{0}}\right)^{2}}} \\
& \delta=\operatorname{acos}\left\{1+\left(\frac{\mu_{2} \omega}{W_{0}}\right)^{2}\right\}^{-\frac{1}{2}}-\operatorname{acos}\left\{1+\left(\frac{\mu_{1} \mu_{2} \omega}{W_{0}}\right)^{2}\right\}^{-\frac{1}{2}} .
\end{aligned}
$$

The decay $\mathrm{e}^{-\frac{W_{0}}{\mu_{1} \mu_{2}} t}$ in Eq. (23) shows the charge/discharge transition with the time constant depending on the flow rate and the volume of cells and tanks. The ratio of cell/tank approaches to 1.0, the time constant becomes larger. Therefore, it is necessary to reduce the flow rate and to enlarge

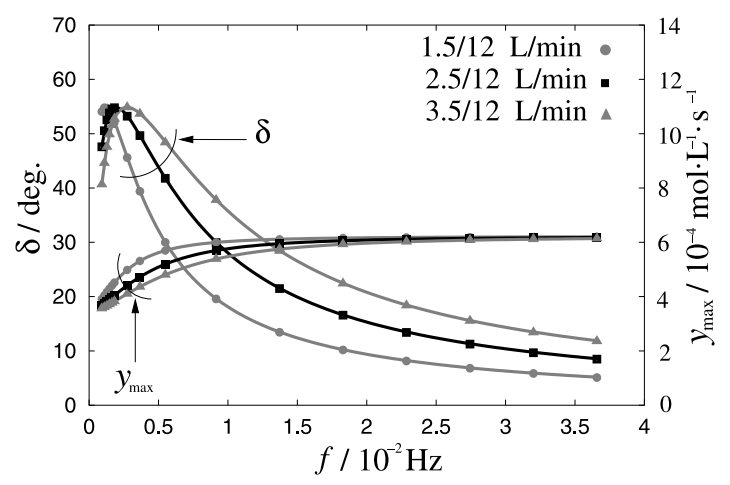

Fig. 6 Electrolysis solution at maximum concentration change and phase difference versus to frequency (current: $30.0 \mathrm{~A}$; flow rate: 1.5/12, 2.5/12, and $3.5 / 12 \mathrm{~L} / \mathrm{min})$.

the product of the volume of cell and tank for keeping the time constant $\left(\mu_{1}<\mu_{2}\right)$. In steady state, the maximum value of concentration change asymptotically saturates as the frequency increases to:

$$
y_{\max }=\frac{i_{0}}{F}(1+K)
$$

$\delta$ has a maximum value when $\omega$ is set at:

$$
\omega=W_{0} \frac{\sqrt{-\left(\mu_{1}^{2}+1\right)+\sqrt{\left(\mu_{1}^{2}+1\right)^{2}+8 \mu_{1} \mu_{2}^{2}}}}{2 \mu_{1} \mu_{2}} .
$$

Here, the relationship between $y_{\max }$ and $\delta$ can be given by:

$$
y_{\max }=\frac{i_{0}}{F}\left\{1+\frac{\gamma \cos \delta}{\mu_{1}}-\frac{\mu_{2} \gamma \cos \delta}{\mu_{1}} \frac{1}{1+\mu_{1}\left(\frac{\mu_{2}}{W_{0}}\right)^{2} \omega^{2}}\right\},
$$

where

$$
\omega^{2}=\frac{ \pm \cos \delta \sqrt{\mu_{2}\left(1+\mu_{1}^{2}\right) \cos ^{2} \delta-2 \mu_{1} \mu_{2}\left(1+\sin ^{2} \delta\right)}}{2 \mu_{1}^{2}\left(\frac{\mu_{2}}{W_{0}}\right)^{2} \sin ^{2} \delta} .
$$

Therefore, the relationship between $\delta$ and $y_{\max }$ follows:

$$
y_{\max }=\frac{i_{0}}{F}\left\{1+\frac{\gamma \cos \delta}{\mu_{1}}-\frac{2 \mu_{2} \gamma \sin ^{2} \delta}{\mu_{2}^{2} \cos \delta \pm \sqrt{\begin{array}{l}
\mu_{2}\left(1+\mu_{1}^{2}\right) \cos ^{2} \delta \\
-2 \mu_{1} \mu_{2}\left(1+\sin ^{2} \delta\right)
\end{array}}}\right\} .
$$

Here, we estimate frequency characteristics of $y_{\max }$ and $\delta$. In this simulation the flow rates of electrolysis solution are set at $1.5 / 12,2.5 / 12$, and $3.5 / 12 \mathrm{~L} / \mathrm{min}$ with $i_{0}=30.0 \mathrm{~A}$, $\gamma=0.1$, and $\mu_{1} / \mu_{2}=1 / 9$. Figure 6 shows their dependence on frequency. In the figure, the points are obtained numerically by the model equation Eq. (22) and the line analytically by Eqs. (24) and (25). The results show the analytical estimation is valuable. The phase differences show their peak at low frequencies. The frequency characteristics possibly 


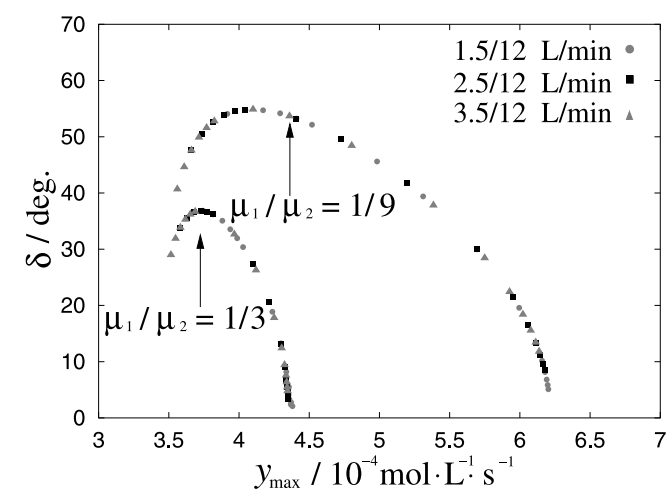

Fig. 7 Relationship between electrolysis solution at maximum concentration change and phase difference (current: $30.0 \mathrm{~A}$; flow rate: $1.5 / 12$, $2.5 / 12$, and $3.5 / 12 \mathrm{~L} / \mathrm{min}$ ).

show the coupled dynamics of the redox flow battery.

Figure 7 shows that the relationship between $y_{\max }$ and $\delta$. Here two volume ratios are selected for simulation at $\mu_{1} / \mu_{2}=1 / 3$ and $1 / 9$. When the ratio of $\mu_{1} / \mu_{2}$ is large, the range of $y_{\max }$ becomes small. The result is natural in consideration of the capacity of solution. However the results give us good information to design the capacity of cells and tanks. As for the frequency response characteristics, the similar feature of loci in phase and terminal voltage is confirmed according to the increase of the frequency in external current. However, in the experimental system there is no practical method to measure the change of ion concentration directly in cells and to confirm the validity. Obviously, the validation is inevitable to complete the modeling of the redox flow battery. Therefore, the experimental research on the dynamics of concentration is necessary with improving the experimental system. That is, it is strongly expected for the proposed model to be general after experimental validation.

\section{Conclusions}

In this paper, a dynamical model of redox flow batteries is proposed and the validity is experimentally confirmed. Based on the model, the transient characteristics of the battery are discussed. The following are the summaries of obtained results.

1) A dynamical model of the redox flow battery is derived for its charging/discharging operation with consideration to the electrical restriction and fluid flow. It was confirmed that the concentration change of electrolysis solution governs the dynamics of the battery dominantly.

2) The model showed good coincidence with experimental data. It showed that the substantial dynamics depend on the flow rate.

3) The frequency response characteristics of the battery were examined. The dependence on the volume ratio was clarified.

These results give us suggestions for design and operation of the redox flow battery. The time delay of flow rate of electrolysis solution in tube and the mixing time at cells and tanks still remain unaccounted for project. In the practical design of the battery the effects should be included in the model further.

\section{Acknowledgment}

This research is partially supported by the 21 st century COE program No.14213201 and GCOE program. The authors would like to acknowledge Professor Tsuyoshi Funaki, Kyoto University, for his wonderful advice on experiments. They would like to show their cordial appreciation to Professor Shogo Shimazu, Chiba University, for his significant suggestions and encouragement on chemical reaction. They also acknowledge the Kansai Electric Power Company and Sumitomo Electric Industries, Ltd. for their support to prepare the tested micro-redox flow battery. They would like to thank Takashi Oka, previous student of Kyoto University, for his cooperation in experiments.

\section{References}

[1] H. Vafiadis and M. Skyllas-Kazacos, "Evaluation of membranes for the novel vanadium bromine redox flow cell," J. Membr. Sci., vol.222, pp.394-402, 2006.

[2] P. Zhao, H. Zhang, H. Zhou, J. Chen, S. Gao, and B. Yi, "Characteristics and performance of $10 \mathrm{~kW}$ class all-vanadium redox-flow battery stack," Power Sources., vol.162, pp.1416-1420, 2006.

[3] K. Enomoto, T. Sasaki, T. Shigematsu, and H. Deguchi, "Evaluation study about redox flow battery response and its modeling," IEEJ Trans. PE, vol.122-B, no.4, pp.554-559, 2002.

[4] T. Homma, "Theoretical studies on transient characteristics of redox flow battery," IEEJ, vol.107-B, no.9, pp.449-456, 1987.

[5] T. Homma, G. Zhao, and Y. Ohsawa, "Theoretical studies on charge and discharge characteristics of redox flow battery," IEEJ, vol.102B, no.6, pp.265-272, 1989 .

[6] T. Sukkar and M. Skyllas-Kazacos, "Water transfer behavior across cation exchange membranes in the vanadium redox battery," J. Membr. Sci., vol.222, pp.235-247, 2003.

[7] M.-H. Li, T. Funaki, and T. Hikihara, "Experimental study on dynamic characteristics of redox flow battery at mode transition between charging and discharging," Trans. ISCIE, vol.21, no.4, pp.129-134, 2008.

[8] M.-H. Li, T. Funaki, and T. Hikihara, "A study of output terminal voltage modeling for redox flow battery based on charge and discharge experiments," The Fourth Power Conversion Conference, no.DS8-1-4, pp.221-225, Nagoya, Japan, April 2007.

[9] M.-H. Li and T. Hikihara, "A fundamental study of redox flow battery based on chemical reaction dynamics," 15th IEEE International Workshop on Nonliner Dynamics Electroni Systems, no.24PM3-24, pp.153-156, Tokushima, Japan, July 2007.

[10] K.J. Vetter, Electrochemical Kinetics, Academic Press, New York, 1967.

[11] A. Negishi, K. Nozaki, and H. Kaneko, "Electrolyte of Vanadium Redox Flow Battery for Load Leveling, Bulletin of the Electromechanical Laboratory," vol.63, no.4, 5, pp.27-34, 1999.

[12] B. Sun and M. Skyllas-Kazacos, "Modification of graphite electrode materials for vanadium redox flow battery application $-\mathrm{I}$. Thermal treatment," Electrochemica. Acta., vol.37, no.7, pp.1253-1260, 1992.

[13] B. Sun and M. Skyllas-Kazacos, "Chemical modification of graphite electrode materials for vanadium redox flow battery application- 
Part II. Acid treatments," Electrochemica. Acta., vol.37, no.13, pp.2459-2465, 1992.

[14] S. Zhong and M. Skyllas-Kazacos, "Electrochemical behaviour of vanadium(V)/(IV) redox couple at graphite electrodes," J. Power Sources, vol.39, pp.1-9, 1992.

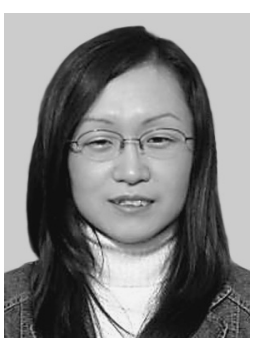

Minghua Li received B.E. degree from Shenyang Agricultural University, China in 1999 and M.E. degree form Kyoto University in 2005 respectively. In Kyoto University, she has been engaged in the research on the modeling and design of redox flow battery. She is a regular member of the IEE, Japan.

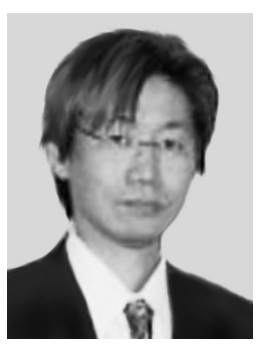

Takashi Hikihara received Ph.D. degree from Kyoto University, in 1990. Since 1997 he has been with Department of Electrical Engineering at Kyoto University, where he is currently a Professor. His research interests include nonlinear science, analysis of nonlinear system, nano-mechanical systems, and power engineering. He is currently an associate editor of Journal of Circuits, Systems, and Computers. He is a regular member of the IEEE, IEE, APS, SIAM, and IEE, Japan. 